\title{
Clickenomics: Using a Classroom Response System to Increase Student Engagement in the Principles of Economics Course
}

\author{
Michael K. Salemi* \\ Department of Economics \\ CB 3305, Gardner Hall \\ University of North Carolina at Chapel Hill \\ Chapel Hill, NC 27599-3305
}

December, 2007

\begin{abstract}
One of the most important challenges facing college instructors of Economics is helping students engage. Engagement is particularly important in the Principles of Economics course where it can help students achieve a long-lived understanding of how economists use basic economic ideas to look at the world. In this paper, I report on how instructors can use Classroom Response Systems (clickers) to promote engagement in the Principles course. I draw heavily on my own experience in teaching a one semester Principles course at the University of North Carolina at Chapel Hill but also report on how others have used clickers to promote engagement. I conclude with evidence that students find clickers very beneficial and with an assessment of the costs and benefits of adopting a clicker system.
\end{abstract}

\section{Introduction}

One of the most important challenges facing college instructors of Economics is implementing strategies to engage students. Engagement is difficult in large enrollment courses where students perceive that they have little or no opportunity to interact with the instructor. Engagement is particularly important in the Principles of Economics course where it can make the difference between obtaining a short-lived and shallow understanding of course concepts, one just sufficient to survive the final examination, and a long-lived understanding of

*The author thanks seminar participants at the Stavros Center, the University of Memphis, and the Teaching Innovations Program for helpful comments on presentations that gave rise to this paper. 
how economists use basic economic ideas to look at the world. Implementing effective engagement strategies is doubly important for an instructor who teaches a large enrollment Principles course.

Hansen, Salemi and Siegfried (2002) argue that the Principles of Economics course should target economic literacy. Salemi (2005) suggests several specific strategies for converting the standard Principles course to one that targets literacy. Both papers argue that students will gain a more robust understanding of basic economic ideas if instructors focus their Principles courses on a shorter list of topics and use the recovered instructional and study time for exercises where students practice using economic ideas.

For the past two years, I have taught a 425 student section of Principles of Economics at the University of North Carolina at Chapel Hill with a course plan that targets literacy. In my course, I use clickers as the cornerstone of my engagement strategy. Interested readers can view my syllabus, power-point slides, and clicker exercises at www.unc.edu/ ${ }^{\sim}$ salemi/Econ101.html. In this paper, I describe how I have used clickers to increase student engagement in my course.

Clickers are personal response pads used by students as part of a Classroom Response System $(\mathrm{CRS})^{1}$. Clickers are handheld radio senders that students use to respond to prompts given by the instructor. A CRS also includes a radio receiver and software that collects responses and stores them in a data base. The typical CRS allows the instructor to make student responses either anonymous or identified and quickly produces histograms that show how students responded to the prompt. When the instructor specifies an identified response, the score deriving from the response is stored in an electronic grade book under the student's name. The Center for Teaching at Vanderbilt University publishes a particularly informative on-line guide to classroom response systems.

There is a growing literature on the use of CRSs. Fies and Marshall (2006) provide a review of the literature on classroom response systems and conclude that there is great agreement that that CRSs promote learning when coupled with appropriate pedagogical methodologies. Beatty (2004) explains in general terms how use of a CRS can transform student learning. He concludes that CRS-based instruction can make students active participants in the learning process, especially when instructors use CRS to develop student understanding rather than recall.

Kaleta and Joosten (2007) provide an overview of how clicker technologies were implemented at four University of Wisconsin campuses. They report that faculty overwhelmingly agreed or strongly agreed that clickers increased student engagement in the classroom, that clickers increased student participation in the course, and that clickers facilitated good interactions among students. They also report that most students agreed or strongly agreed that clickers led them to become engaged in the class, that clickers increased the frequency of their participation in the course, and that clickers helped them pay attention.

\footnotetext{
${ }^{1}$ The author uses the Classroom Performance System (CPS) offered by eInstruction. Other examples of CRSs are the Turning Point system offered by Turning Technologies and PRS interwrite which has recently merged with eInstruction.
} 
All surveyed faculty either agreed or strongly agreed that clickers allowed them to assess student knowledge of particular concepts. Seventy-five percent of surveyed students agreed or strongly agreed that clickers helped them get instant feedback on what they knew and did not know. Over half the surveyed students agreed or strongly agreed that clickers were beneficial to their learning.

In the remainder of this paper, I will explain how instructors can use clickers to increase student engagement in the Principles of Economics course. In Section 2, I will provide examples of standard and non-standard strategies for the use of clickers. In Section 3, I will provide evidence that shows that the use of clickers does improve engagement. The last section outlines the benefits and costs of using a CRS.

\section{Clicker Strategies for the Principles Course}

In this section of the paper, I provide examples of several strategies that use clickers to increase student engagement. Where possible, I provide examples from my Principles of Economics course. I organize clicker strategies under five headings: Sampling Student Opinion, Asking Are-You-With-Me Questions, Acquiring Economic Data From Students, Peer Instruction Activities, and Games and Simulations.

\subsection{Sampling Student Opinion}

Classroom reponses systems are an educational offshoot of audience response systems. Firms use audience response systems to conduct sales meetings, hold focus groups, test new products, and conduct planning or team building sessions. In an educational context, sampling student opinions can be a useful tool for motivating student interest and for gauging the impact of a presentation.

I devote the first lecture of my Principles course to opportunity cost and the benefit-cost principle. I begin the lecture by asking the students whether the aphorisms listed in Table 1 are true or false ${ }^{2}$.

Table 1

Sampling Student Opinion

\begin{tabular}{lcc}
\hline \hline & \multicolumn{2}{c}{ Fraction True } \\
Statement & Start & End \\
The best things in life are free. & .52 & .32 \\
The biggest part of the cost of college is tuition and fees. & .44 & .12 \\
Anything worth doing is worth doing well. & .78 & .34 \\
Life should be sustained at any cost. & .42 & .19
\end{tabular}

The purpose of asking students whether "the best things in life are free" is, of course, to introduce them to "opportunity cost" and to make them sensitive to the special meaning of the word "free" in economics. It is heartening to learn

\footnotetext{
${ }^{2}$ I learned this strategy from Robert Reinke.
} 
that at the end of the lecture, the fraction of students who thought the best things in life were free fell from 52 to 32 percent. The purpose of asking students whether tuition and fees count for the biggest share of the cost of attending college is to make them aware of the opportunity cost of their time. For most students paying in-state tuition and fees at $\mathrm{UNC}-\mathrm{CH}$, the opportunity cost of time is larger than the direct costs of college. Asking students whether anything worth doing is worth doing well helps introduce the benefit-cost principle which implies that for most activities marginal costs rise above marginal benefits before all possibilities are exhausted. Finally, I ask students whether life should be sustained at any cost to make them aware that opportunity cost is relevant even when making decisions about preserving life. I point out to them that the opportunity cost of providing an expensive surgery to a poster-child patient may be withholding malaria treatment from thousands of other children.

It is very valuable for me and for my students to be able to learn how the lecture on opportunity cost and the benefit-cost principle changed the opinions of members in the class. From these results, I learn that I changed some, but not all, opinions which tells me that it is important to continue explaining these two basic concepts and illustrating their use. From these results, students learn that some of their fellow students think that the course material is relevant and that the instructor cares what they think. Both of these messages promote engagement.

Displaying data on student opinions like that reported in Table 1 creates teachable moments. Instructors can ask students who changed their mind why they did so. They can ask students who did not change their minds why they are holding on to their original view and what additional information they would need in order to be willing to change their view.

I use a variation on opinion sampling in the part of my course devoted to externalities and pollution. Students read Eight Great Myths of Recycling by Daniel Benjamin in which the author makes an economic case against mandatory recycling. To motivate interest and demonstrate the applicability of Benjamin's arguments, I hold a "town hall meeting" during class where students may speak for or against a proposition that was passed by the town of Carrboro, North Carolina, a nearby neighbor of Chapel Hill where many UNC students live. The proposition states: "Now, therefore, be it resolved by the Board of Alderman of the Town of Carrboro: The Board of Alderman supports the creation of a Zero Waste Plan in order to eliminate waste and pollution in the manufacture, use, storage, and recycling of materials" (Carrboro, 1998). After the town hall meeting, students vote on the proposition with their clickers. During my Fall 2007 course, 72 percent of students voted against the proposition.

Another variation of opinion sampling can be used in the parts of the course devoted to economic policy. The big monetary policy story of Fall, 2007 was the Fed's reaction to the so called sub-prime lending crisis. On September 18, 2007, the Fed cut the federal funds rate by a larger-than-expected onehalf point. It then cut the funds rate again by a quarter point on October 30 saying that this cut balanced the risks between inflation and unemployment. On November 28, 2007, Donald Kohn, vice chairman of the Fed Board of Governors, 
said that recent turbulence in the credit markets had "partly reversed some of the improvement in market functioning" that was seen in the weeks after the October 30 cut (Reddy, 2007). Many market analysts interpreted Kohn's statement to mean that the Fed was planning another rate cut for December, 2007. Not all economists agreed that rate cuts were appropriate. Janice Revell of Money Magazine warned that "The Fed's actions could very well be ushering in a new era of inflation - and that is horrible news for your retirement portfolio" (Revell, 2007).

Clickers provide a nice way to help students think carefully about what is at stake in a policy decision. After students read the news article about Kohn's speech and the opposing opinion of Revell, an instructor could ask students what the Fed should so. For example, the instructor could ask the clicker question presented in Table 2 .

Table 2

Sampling Student Opinion about a Policy Issue

At its meeting in December 2007, the Federal Open Market Committee should...

A. Lower the federal funds rate by one-half percent.

B. Lower the federal funds rate by one-quarter percent.

C. Leave the federal funds rate unchanged.

D. Raise the federal funds rate by one-quarter percent.

E. Raise the federal funds fate by one-half percent.

Forcing students to take a stand on a soon-to-be made decision by the Federal Reserve is an excellent way to promote engagement with the material. The ratecut controversy occurred too late for me to take advantage of it. But it put me on the lookout for policy issues that are relevant to the course and are being discussed in the media as the course goes on.

\subsection{Asking Are-You-With-Me Questions}

The most common use of clickers in the classroom is asking questions that help the instructor and students judge whether they have understood recently presented material.

Asking are-you-with-me questions provides several benefits. First, when the correct answer is displayed, students receive feedback on whether or not they have understood the target concepts. Second, when the histogram of responses is displayed, the instructor receives feedback on how well students have understood the target concepts. Instructors can adjust their presentations by reteaching the concept or by explaining why a popular wrong options is wrong. In my experience, students who chose a wrong option often ask about it after class providing another opportunity for the instructor to help students correct mistakes in their understanding. Third, asking are-you-with-me questions creates an incentive for students to come to lectures and pay attention while they are there. In the next section, I will provide data on attendance in my Principles course that show that students responded positively to this incentive. Fourth, 
asking are-you-with-me questions during lecture breaks the lecture into chunks (Saunders, p.90). I allow students to discuss the question among themselves before sending their answers. The questions serve as breaks during which students switch from passive to active mode and thereby refresh themselves. The are-you-with-me questions are another way in which the use of a CRS system promotes engagement. Students learn that they are expected to be thinking during the lecture, explaining their reasoning to their neighbors and translating their thoughts into responses. Fifth, asking are-you-with-me questions allows the instructor to illustrate the level of mastery that he expects students to develop in a small stakes setting.

Table three shows an are-you-with-me question that I ask during the first class of the semester.

Table 3

An Are-you-with-me Question from the Opportunity Cost Lecture

Raleigh Politicians have proposed a new convention center. They suggest paying for it by raising the hotel tax. They argue that the project will be free to voters since out-of-town visitors will pay for it. Which of the following best explains why the convention center is not free to Raleigh citizens?

A. The tax increase will cause a reduction in visits to Raleigh.

B. Cost overruns are common with public projects.

C. The marginal benefit of the project exceeds the marginal cost.

D. The tax funds could be used for other projects.

Students do not find this question easy. Only 52 percent answered correctly when I asked this question after explaining opportunity cost. Those who answered incorrectly distributed themselves evenly across the distracting options. The lesson here is that instructors can say that "decision makers face an opportunity cost when scarce resources have alternative uses" until they are blue in the face and some students will not be able to transfer these words into an understanding of what opportunity cost means in a new context. Asking are-you-with-me questions provides students an opportunity to practice using concepts in new settings. I invite readers interested in learning more about the are-you-with-me questions from my course to visit my web page (www.unc.edu/ ${ }^{\sim}$ salemi/Econ101.html).

During Fall, Semester 2007, I asked approximately ninety are-you-with-me questions during 25 lectures, an average of just under four questions per lecture. As a remedy for occasional response pad problems and student illness, I counted only the top 90 percent of each student's responses, summed those and scaled the total so that it accounted for ten percent of the course grade. Figure 1 gives the distribution of scaled scores. 
Figure 1

Are-you-with-me Question Score Distribution

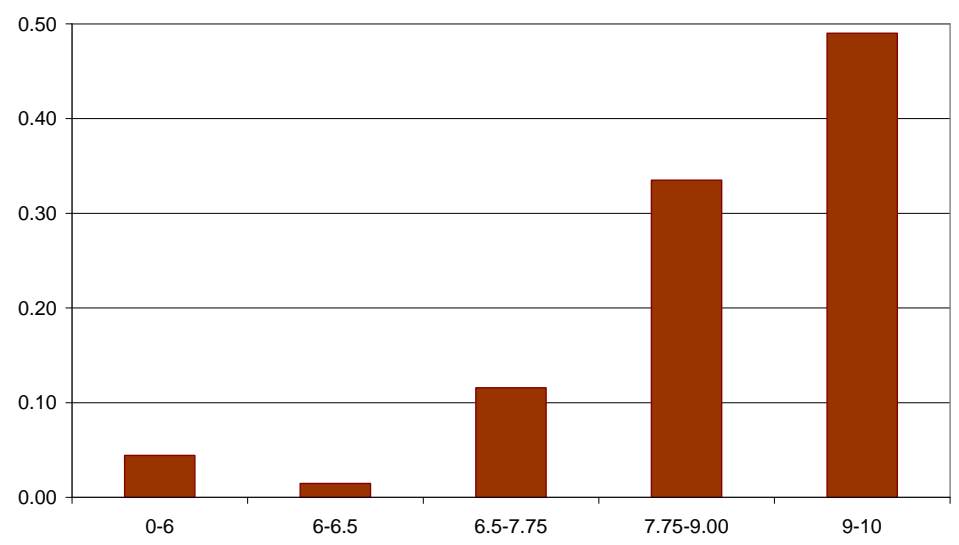

The figure shows that nearly 50 percent of students earned a grade between nine and ten (A) on CRS graded assessments while another 32 percent earned a score between 7.75 and 9 (B). I designed the rules for CRS assessments so that a grade distribution like that in Figure 1 would result. In particular, I encouraged students to talk with their neighbors before deciding on their own response. I asked questions that were of medium difficulty as a way of encouraging students. And, I used CRS scores as a measure of effort that would help students whose performance on examinations placed them near but below a grade cutoff. ${ }^{3}$

\subsection{Acquiring Economic Data From Students}

In most economics courses, there is a disconnect between the examples used in class and applications of economics in real world settings. For example, in order to make demand and supply examples simple and diagrams easy to draw, text book authors typically assume linear relationships between the quantity demanded and price. An alternative is to conduct a market experiment using the CRS system that obtains student reservation prices and to use these data to derive a class demand schedule. Bergstrom (2007, p.7) describes a thought experiment in which he asks students: "What is the most you would be willing to pay to have an iPod if you didn't have one and couldn't get one any cheaper than this price?" While Bergstrom's thought experiment is useful, I believe students

\footnotetext{
${ }^{3}$ Econ 101 at UNC-CH requires students to attend two 75 minute lectures and one 50 minute recitation per week. Recitations are supervised by graduate teaching assistants. Each recitation section includes about 25 students. I based grades in my Principles course on a student's total score out of 100 possible points: 25 for each of two midterm exams, 30 for the final exam, and 10 each for recitation and CRS assessments. The recitation grade was based on two quizzes, a journal in which students explained how economics applied to several news articles, and a component that measured how often and well students contributed to discussion in their recitation sections. The course grade distribution was A (13\%), B (51\%), $\mathrm{C}(26 \%), \mathrm{D}(8 \%)$ and $\mathrm{F}(2 \%)$.
} 
will report more accurately their reservation prices if they are confronted with an actual economic decision rather than a virtual one.

Each semester I choose a good to auction off during the fifth class of the semester $^{4}$ when I first introduce demand and supply. This past semester I auctioned off a logo T-shirt from the University of California at Santa Cruz which displays the Banana Slug mascot of UC-SC. Most students recognize the shirt as one worn by John Travolta in the film Pulp Fiction. The shirt is not easily obtained in Chapel Hill. The auction is a second-price auction where the winner is the highest bidder but pays the second-highest bid to obtain the shirt. In a second price auction, it is rational to bid one's reservation price. Thus, using a second-price auction allows me to observe the reservation price of each student in the class. Before I conduct the auction, I explain the concept of "reservation price" and offer a number of examples. I also use a text, Frank and Bernanke (2007), which emphasizes that reservation prices are the building blocks of demand and supply schedules.

Students enter their bids (reservation prices) with their clickers. ${ }^{5}$ I have conducted this auction twice. The first time the winning bid was $\$ 35.50$. This semester it was $\$ 32.00$. Figure 2 displays the demand schedule implied by the bids that students made.

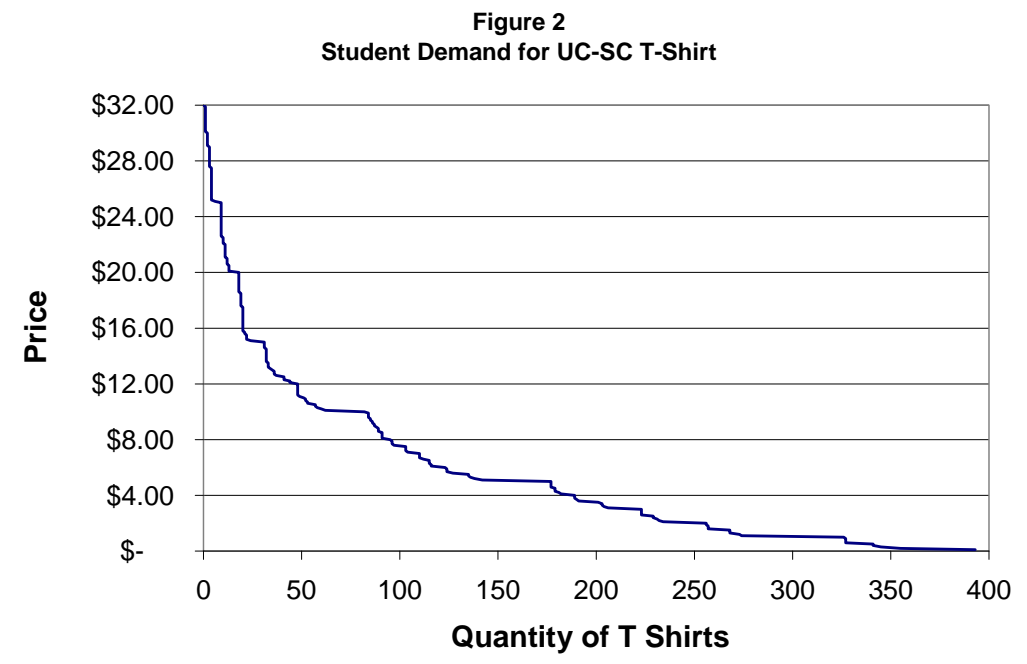

The T-shirt auction is one of the most effective exercises I have ever used to teach economics. Every student in the class can see the price at which they entered the competition for the shirt. They can verify that the great majority of students in the class were willing to pay no more than $\$ 10.00$ for the shirt

\footnotetext{
${ }^{4}$ Because I target my Principles course to improve the economic literacy of students, I devote four lectures to opportunity cost, the benefit cost principle and comparative advantage. A copy of my syllabus is available on my course web page.

${ }^{5}$ I use the eInstruction CPS system with clickers that allow floating point number responses.
} 
but that a few valued it much more highly. At the end of the auction, once the winning bidder is identified and the shirt awarded ${ }^{6}$, the time is ripe for a discussion about why reservation prices differ across students and whether the instructor somehow "ripped off" the winning bidder. When some students appear outraged that anyone would pay over $\$ 30.00$ for the shirt, I ask the winning bidder why they bid so high and whether they would like to recant their bid. Invariably, the winner has a very good reason for their bid and does not want to recant. This discussion turns the auction into an opportunity to demonstrate that different students have different tastes and that "being different" is not the same thing as "being irrational."

The T-shirt auction data can also be used to illustrate price setting by a seller with market power. Later in the course, I pose the following question: "Suppose I could buy the Banana Slug T-shirts for $\$ 12.00$ each and face the demand schedule from the auction. What price should I set and how many shirts would I sell if I wanted to make as much profit as possible?" By assumption, the marginal cost of a shirt is $\$ 12.00$. But what is the marginal revenue schedule implied by the class demand schedule displayed in Figure 2? The marginal revenue schedule is highly irregular in contrast to the straight line implied by the text-book linear demand schedule. In fact, it is folly to attempt to find the profit maximizing price by applying the first order condition. Instead, one can use excel to compute profit on a case by case basis. Doing so results in Figure 3.

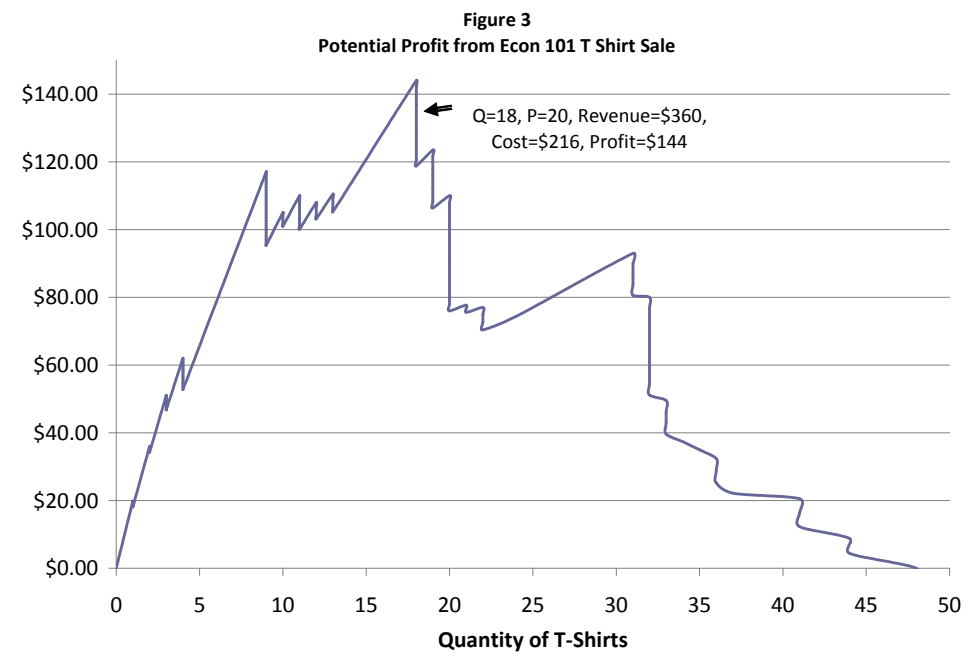

A profit-maximizing shirt seller would charge $\$ 20.00$ for a shirt, sell 18 shirts, and make a profit of $\$ 144.00$. I think this extension to the T-shirt auction

\footnotetext{
${ }^{6} \mathrm{I}$ award the shirt to the winning bidder immediately at the conclusion of the auction. I accept the bidders promise to pay at the beginning of the next class if necessary. I always insist on payment for the shirt and make a show of receiving that payment. It is essential that everyone understands that the transaction is real.
} 
exercise is also valuable because it requires students to think outside the textbook box. ${ }^{7}$ Indeed, one student came up after class and questioned whether it made sense to use the demand schedule derived from the class auction as a basis for estimating the profitability of a multi-shirt sale. The student argued that the value of a shirt to members of the class would fall when they understood that the winner would not be the only student to acquire the shirt. The student said that the shirt came with "bragging rights" that would be lost with a multishirt sale. Clearly, at least one student was thinking deeply about the meaning of demand.

\subsection{Peer Instruction Activities}

Mazur (1997) introduces peer instruction (PI), a teaching strategy designed to keep students engaged in a large enrollment lecture course. As clicker technology advanced, Mazur and others adapted PI so that it could be implemented with a CRS. In a CRS-PI classroom, lectures consist of short presentations on key concepts. Each presentation is followed by a concept test which asks multiple choice questions that students answer with clickers. After students record their initial answers to a question, the instructor displays the histogram of responses. Students then discuss their answers with their neighbors. After several minutes of discussion, students re-answer the same question with their clickers and the instructor again displays the histogram of responses. The instructor then resumes the lecture with comments on the question and the responses.

Crouch et al. (2007) report on what has been learned from teaching the nonmajors introductory physics course with PI over the past ten years. They find that gains in student understanding are greatest when PI is combined with other strategies that increase student engagement and that most instructors have had success using PI. Lucas (2007) finds that the PI-clicker combination is very effective in enhancing student engagement and learning in college calculus classes. Ghosh and Renna (2007) describe a pilot project at the University of Akron in which clickers and PI were combined to teach courses in 23 departments by 45 instructors including one instructor who taught Principles of Microeconomics and another who taught Principles of Macroeconomics. Ghosh and Renna provide examples of concept test questions that they used and report that students responded to concept tests with enthusiasm. In an exit survey, over 70 percent of students agreed or strongly agreed that the concept tests reinforced important class concepts and increased their willingness to ask questions. Over sixty percent either agreed or strongly agreed that they would recommend continued use of the concept tests.

How, in particular, would an instructor implement PI with a Classroom Response System? In the planning phase, the instructor would organize each lecture around several key concepts and would write one or more multiple choice questions that test student understanding of the key concept. For example, the

\footnotetext{
${ }^{7}$ In an honors section of Principles or in an Intermediate Microeconomics course, I would give the data to the students and ask them to find the profit maximizing price and quantity. I judged that such an exercise was outside the curriculum for my literacy targeted course.
} 
question reported in Table 3 tests student understanding of opportunity cost in the context of a public policy decision. During class, the instructor would present a mini-lecture on opportunity cost and then ask students to respond to the Table 3 question with their clickers and without discussing the question with their neighbors. The instructor would then display the histogram of responses and allow students to discuss their answers with their neighbors. After three to four minutes of discussion, the instructor would ask the question again and students would again respond with their clickers. The instructor would display the response histogram a second time, preferably together with the original histogram, comment on the results, and then resume the lecture.

Ghosh and Renna report that the fraction of correct responses in their Principles courses typically increased between the first and second asking of a concept test question. When asked a question about shifts in aggregate demand and supply, 55 percent of students answered correctly in round one and 97 percent in round two. When asked a question about how to read profits from a schedule displaying price, marginal cost and average cost, 43 percent of students answered correctly in round one and 89 percent answered correctly in round two.

Mazur (1997) recommends that concept test questions not be graded arguing that students are more willing to share ideas and learning is thus better promoted when grades are not involved in peer instruction concept tests. Mazur's recommendation implies that instructors may want to separate concept tests from are-you-with me questions and use both during a typical lecture. By not grading the concept test questions, the instructor would lessen the gradecompetition incentive for students to keep their understanding to themselves. By grading the are-you-with-me questions, the instructor would provide an incentive for students to attend regularly and pay attention. In my own class, I have yet to implement peer instruction but intend to do so when I next teach the course. I will particularly be interested in assessing the value added of peer instruction concept tests in a course that routinely asks graded are-you-with-me questions.

\subsection{Games and Simulations}

Bergstrom (2007) introduces the possibility of conducting classroom games, simulations and experiments via a CRS. He describes a traffic congestion game in which commuters drive between their homes in a factory town and the factory by one of two routes. Route A is shorter but subject to congestion as the number of commuters using it grows. Route B is longer and capable of handling unlimited users without an increase in travel time. Students are told to minimize their travel time and then are allowed to choose their route using their clickers.

The game is calibrated so that travel time on route $\mathrm{A}$ is less than or equal to travel time on route B as long as 150 or fewer students choose route A. The game takes place over several trips. After each trip, the instructor observes the number of students who chose each route, computes travel times, reports these, and allows time for reflection. The instructor then allows students to choose 
their routes for the next trip.

Bergstrom finds that the number of students choosing the shorter but congestionprone route does not converge to 150 but oscillates around that value. When students learned that taking the shorter route led to a shorter commute time, they were more likely to choose the shorter route. When they learned that choosing the congestion-prone route led to a longer commute time, the number choosing the longer, constant-time route eventually increased. Bergstrom notes that this result is similar to results obtained by others who have run the traffic congestion game.

Unfortunately, there is not yet available a mechanism for easily conducting games and simulations with a CRS. The problem is to capture the game plays of students, convert them to data that is meaningful in the context of the game, use the data to update the state of the game, and report the new game state to students. Adapting games and simulations to a classroom response system will make this already very useful teaching technology more useful still.

\section{$3 \quad$ Do Clickers Increase Student Engagement?}

Fies and Marshall (2006) conduct a meta-study on the use of CRSs and conclude that there is great agreement that classroom response systems promote learning when coupled with appropriate pedagogies. Crouch et al. (2007, p.22) report that "...students grasp of the course material improves according to a number of different measures: two standard tests, the Force Concept Inventory and the Mechanics Baseline Test...both during class and when tested for retention at the end of the semester." The use of clickers in the Principles of Economics course is relatively new and I could find no studies that measure the impact of clicker use on learning there. Nevertheless, readers may be interested in less scientific evidence from my own course.

It is apparent that use of the clicker system raised attendance in my Principles course above the levels reported by colleagues who do not use the system. During Fall semester 2007, I took attendance by clicker in 26 out of 29 class meetings. I did not take attendance with clickers on the first class day or on either of the two days when students sat for mid-semester exams. I began the semester with 423 students enrolled in the course. During the first week of classes, several students dropped the course while others added leaving the total at 423 . I ended the semester with 406 students for a stick rate of 96 percent. Of the students who stuck with the course, the average number of classes attended was 23.8. However, absences were concentrated among a few students. The median number of classes attended was 25 of 26 and 83 percent of students were present at 23 classes or more. Only eight percent of students were marked present at fewer than 20 classes. As remarkably good as these attendance data are, they slightly understate true attendance because students who forgot their clickers or had a clicker malfunction were not marked present by the CRS.

At UNC-Chapel Hill, Principles of Economics is taught as a one semester course. Students attend either two 75 minute or three 50 minute lectures and 
one 50 minute recitation per week. Graduate student teaching assistants (TA) teach recitations in sections of about 30 students each. One of the most difficult problems faced by TAs is coaxing students to participate in their recitations. Especially at the beginning of the semester, students are reluctant to talk and TAs must work very hard to obtain any spoken contributions.

The reality in the recitation sections of my Principles course is different. TAs report that students reach their first recitation meeting eager to talk about whether "life should be sustained at any cost" and whether "the best things in life are free". I attribute the difference in student engagement in recitations primarily to the use of the CRS which encourages students to participate from the first day of class and signals to them that the instructor and TAs are paying attention to their views and performance. The willingness to speak is not limited to recitation. Students frequently ask questions during the lecture and are willing to repeat their questions when I bring the microphone to them. Students are also willing to respond to questions I put to them-even though they are answering in front of 400 other students. I do not contend that my 400 student course is as intimate as a 25 student seminar. I do believe that by using clickers I have created an environment in which students are more willing to discuss their ideas with their peers and speak out in front of the class.

In the last class meeting of my Fall 2006 Principles course, I asked students to complete the standard UNC-CH course evaluation. Our course evaluation allows the instructor to add questions of his own and I asked students their views on the use of clickers in our course. I aksed students to strongly disagree (SD), disagree (D), ..., strongly agree (SA) with three statements about engagement and the use of clickers. The responses of my students are reported in Table 4.

Table 4

Student Evaluation of Clickers

\begin{tabular}{lccccc}
\hline \multicolumn{1}{c}{ Statement } & \multicolumn{5}{c}{ Response } \\
& $\mathrm{SD}$ & $\mathrm{D}$ & $\mathrm{N}$ & $\mathrm{A}$ & $\mathrm{SA}$ \\
& - & .05 & .11 & .52 & .32 \\
The instructor effectively encouraged & - & & & & \\
students to participate in class. & - & & & & \\
The use of clickers helped me learn. & - & .04 & .07 & .51 & .37 \\
$\begin{array}{l}\text { The instructor should continue to } \\
\text { use the clickers in the future. }\end{array}$ & - & & & & \\
& - & .04 & .06 & .46 & .43
\end{tabular}

Student support for the use of clickers in evident in the responses. Nearly 90 percent of students recommend their continued use. I asked the same supplementary questions in the student evaluation this semester. The results will be available in mid-January, 2008

\section{Conclusions}

For many readers, the most important question about clickers will be: Does adoption of a CRS and the use of clickers pass a benefit-cost test. I conclude with an assessment of the costs and benefits for teaching Principles of Economics. 
Because I use the Classroom Performance System (CPS) offered by eInstruction, I will provide cost information about that system.

The costs of using a CRS are of two types: direct costs of the system and time costs for instructors and students. I assume that the instructor will use the CRS in a classroom with a projector that can be driven by a laptop computer. ${ }^{8}$ The direct costs of the system are the cost of the clickers themselves and the cost of registering them for use in the course. Students typically pay between $\$ 20.00$ and $\$ 30.00$ for their clickers. At UNC-CH, students purchase clickers at the campus bookstore for $\$ 21.35$. Students may use clickers in multiple courses throughout their college career. For each clicker course, students pay a separate registration fee of between $\$ 6.00$ and $\$ 15.00$. EInstruction allows students to register clickers for an entire year or for four four years at a flat rate. Typically, clicker companies provide the radio receiver and software for the CRS to instructors without charge.

The larger costs are the time costs for instructors and students. In my view, a CRS system works best when the instructor is supporting lectures with power point presentations. CPS sits on top of the instructor's powerpoint presentations. The instructor engages a powerpoint presentation from within CPS and has available a CPS toolbar to initiate questions. Instructors who already use powerpoint face two costs associated with the adoption of a CRS. First, instructors must design or redesign their lectures to allow for clicker activities. It is not sufficient simply to make space for CRS activities. It is necessary to organize or reorganize material in a way that exploits the educational benefits of using a CRS. For example, the auction exercise described above has greater educational value if the instructor first presents "reservation prices" and explains the connection between reservation prices and a demand schedule.

Second, instructors must design the clicker activities themselves. Here, I recommend a gradual approach. Instructors could begin by writing a few areyou-with-me questions for each lecture. They could next choose a few lectures where polling student opinion makes sense. They could then choose some lectures where they believe peer instruction would help students better understand difficult but important concepts and write more challenging questions as the basis for peer instruction activities. Instructors who teach their courses without powerpoint but want to adopt a CRS have two options. They can convert their lectures to powerpoint or they can use their CRS solely for clicker activities. In that case, instructors switch between whatever projection system they are using to support their lectures and the CRS system each time they begin a clicker activity.

Students face minimal time costs associated with the use of clickers. They must take the time to buy and register their clickers. They must take the trouble to bring their clickers to each class. Occasionally, they must trouble

\footnotetext{
${ }^{8}$ If the classroom projector is driven by a classroom CPU, it will be necessary for the instructor to install the CRS software on the classroom computer. Because the software will keep the gradebook for the course on the computer where the software is installed, it will be essential for the instructor to password protect the CRS files and to download backup copies of the gradebook via a flash drive.
} 
shoot problems with the clickers by replacing the batteries or visiting the CRS company web site. If they lose their clicker or if their clicker fails, students must take the time to replace it.

For me, the benefits of a CRS system far outweigh the costs. Indeed, it is my view that the current generation of CRS is the most important advance in education technology to occur in the past 30 years. Instructors are different and readers must decide for themselves whether the benefits of using clickers outweigh the costs.

\section{References}

[1] Beatty, Ian, "Transforming Student Learning with Classroom Communication Systems," EDUCAUSE Center for Applied Research, Boulder Colorado, Research Bulletin, Volume 2004, Issue 3, 2004.

[2] Benjamin, Daniel K., Eight Great Myths of Recycling, PERC, Bozeman, Montana, 2003, 1-32.

[3] Bergstrom, Ted, "Teaching Economics Interactively: A Cannibal's Dinner Party," University of California eScholarship Repository (http://repositories.cdlib.org/ucsbecon/berstrom/2007c), 2007.

[4] Caldwell, Jane E., "Clickers in the Large Classroom: Current Research and Best Practice Tips," CBE-Life Sciences Education,6 (Spring 2007), 9-20.

[5] Carrboro, North Carolina, "A Resolution Supporting Creation of a Zero Waste Plan," September 22, 1998, http://www.grrn.org/zerowaste/CZWRes.html.

[6] Crouch, Catherine H., Jessica Watkins, Adam P. Fagen and Eric Mazur, "Peer Instruction: Engaging Students One-on-one, All at Once," in Redish, E. F. and P. Cooney (eds.), Research-Based Reform of University Physics, 1 (1), 2007, http://www.compadre.org/PER/per_reviews/volume1.cfm

[7] Elliot, Caroline, "Using a Personal Response System in Economics Teaching," International Review of Economics Educations, 1 (1), 2003, 80-86.

[8] Fies, Carmen and Jill Marshall, "Classroom Responses Systems: A Review of the Literature," Journal of Science Education and Technology," 15 (1), 2006, 101-09.

[9] Frank, Robert H. and Ben S. Bernanke, Principles of Economics, McGrawHiil/Irwin, New York, 2007.

[10] Ghosh, Sucharita and Francesco Renna, "Using Electronic Response Systems in Economics Classes," University of Akron Working Paper, Sep;tember 2007. 
[11] Hansen, W. Lee, Michael K. Salemi and John Siegfried, "Use It or Lose It: Teaching Literacy in the Economics Principles Course," American Economic Review, Papers and Proceeding of the American Economic Association, 92 (2), 2002, 463-72.

[12] Kaleta, Robert and Tanya, Joosten, "Student Response Systems: A University of Wisconsin System Study of Clickers," EDUCAUSE Center for Applied Research, Boulder Colorado, Research Bulletin, 2007 (10), 2007.

[13] Lucas, Adam, "Using Peer Instruction and I-Clickers to Enhance Student Participation in Calculus," St. Mary's College of California Working Paper, 2007, http://dillgroup.ucsf.edu/ alucas/.

[14] Mazur, Eric, Peer Instruction: A User's Manual, Prentice Hall, Englewood Cliffs, N.;J., 1997.

[15] Reddy, Sudeep, "Fed's Hints of a Rate Cut Cheers Markets," Wall Street Journal, November 29, 2007, Page A1.

[16] Revell, Janice, "Why the Fed's Rate Cut Should Scare You," Money Magazine, November 2, 2007, http://money.cnn.com/2007/11/02/pf/retirement/revell.moneymag/

[17] Salemi, Michael K., "Teaching Economic Literacy: Why, What and How," International Review of Economics Education, 4 (2), 2005, 46-57.

[18] Saunders, Phillip, "Learning Theory and Instructional Objectives," in Walstad, William and Phillip Saunders (eds.), Teaching Undergraduate Economics: A Handbook for Instructors, Irwin McGraw-Hill, New York, 1998.

[19] Vanderbilt University Center for Teaching, "Classroom Response Systems," http://www.vanderbilt.edu/cft/resources/teaching_resources/technology/crs.htm. 